\title{
Avaliação da vulnerabilidade ambiental como instrumento de gestão costeira nos municípios de Belmonte e Canavieiras, Bahia
}

\author{
Dária Maria Cardoso Nascimento ${ }^{1}$ \& José Maria Landim Dominguez ${ }^{2}$
}

\begin{abstract}
Resumo O artigo trata do mapeamento da vulnerabilidade ambiental dos municípios de Belmonte e Canavieiras, situados no litoral Sul do estado da Bahia. Nas duas últimas décadas atividades econômicas como silvicultura, carcinicultura e turismo expandiram-se na região ocupando área de terrenos com graus variados de vulnerabilidade, causando degradação nos ecossistemas. Nesta pesquisa foram originados índices de vulnerabilidade ambiental a partir da integração das características geológicas (tempo geológico e fragilidade), de solos (maturidade pedogenética), declividade (variação de declividade), uso da terra e vegetação (proteção da paisagem e biodiversidade da biota). Para cada diferente feição de mapeamento foram atribuídos pesos de 1 (menos vulnerável) a 5 (mais vulnerável). Estes mapas foram manipulados algebraicamente em um ambiente Sistema de Informação Geográfica (SIG) na escala de 1:100.000. O produto final em formato "raster" foi reclassificado em 5 classes de vulnerabilidade ambiental, assim identificadas: baixa, baixa a média, média, alta e muito alta vulnerabilidade. A classe muito alta inclui os manguezais, às várzeas flúviolagunares e a linha de costa. Nas classes que apresentaram a vulnerabilidade ambiental baixa estão incluídos os tabuleiros costeiros (Grupo Barreiras), recobertos pela floresta ombrófila (mata atlântica). O mapa de vulnerabilidade ambiental produzido permite a compreensão dos diferentes graus de fragilidade de cada unidade mapeada, podendo ser utilizado como instrumento de gestão costeira para o desenvolvimento local e regional.
\end{abstract}

Palavra-chave: Vulneralidade ambiental, Gestão costeira, Sistema de Informação Geográfica, Belmonte e Canavieiras.

\begin{abstract}
Environmental vulnerability evaluation as a tool for coastal management in the Belmonte and Canavieiras municipalities, state of Bahia, Brazil. This paper presents an environmental vulnerabillity map for the Belmonte and Canavieiras municipalities, southern littoral of Bahia state. During the last two decades economic activity related to silviculture, aquaculture and tourism expanded in this region occupying an ever increasing area of lands with varied degrees of vulnerability, thus causing degradation of ecosystems. In this research we derived environmental vulnerability indices though the integration of geological characteristics (age and degree of induration), soils types, terrain slope, and land use and cover. To each of the different features mapped weights were attributed ranging from 1 (least vulnerable) to 5 (most vulnerable). Algebraic manipulation of the different maps was carried out in a Geographic Information System (GIS) environment in a 1:100.000 scale. The final raster product was re-classified into 5 vulnerability classes: low, low to medium, medium, high and very high vulnerability. The very high vulnerability class includes mangrove swamps, riparian wetlands and the shoreline. Low vulnerability classes comprise areas of the coastal tablelands (Barreiras Group) with a maritime forest (mata atlântica) cover. The environmental vulnerability map produced allows a better understanding of the different degrees of fragility associated with each environmental unit mapped, and can thus be used as a tool for coastal management and local and regional planning.
\end{abstract}

Keywords: Environmental vulnerability, Coastal management, Geographic Information System, Belmonte and Canavieiras.

INTRODUÇÃO As zonas costeiras têm sofrido, em todo o mundo, agressões decorrentes do adensamento da população urbana e dos efeitos da ocupação, e dos diversos usos subseqüentes, com reflexos: (i) no equilíbrio de seus ecossistemas, colocando em risco a biodiversidade marinha e terrestre; (ii) na alteração da dinâmica dos processos costeiros, com perda de áreas habitadas; e (iii) no agravamento dos conflitos ambientais, exigindo-se ações mais efetivas do poder público quanto ao reordenamento desses espaços litorâneos (World Resources Institute 2001).

A Declaração de Estocolmo, em 72, marca os estudos de análise ambiental, voltando-se à gestão do território, passando então esses estudos a serem produzidos com abordagem integrada (Brailovsky 1978, Tricart 1977), no sentido de mensurar a capacidade ambiental de adaptar-se às novas atividades produtivas, com o menor risco de degradação.

1 - Universidade Federal da Bahia, Departamento de Geografia, àrea Geociências/Geografia Física, Salvador (BA), Brasil.

E-mail: daria@ufba.br

2 - Universidade Federal da Bahia, Centro de Pesquisa em Geofísica e Geologia CPGG, Salvador (BA), Brasil. E-mail: landim@ufba.br 
Os problemas ambientais delineados na década de 70 movem também a União Geográfica Internacional, através de uma Comissão Internacional de Cartografia e do Meio Ambiente e de sua Dinâmica, para a produção de cartas/mapas ambientais em diversas escalas em muitos paises do mundo (Journaux 1975). As cartas ambientais surgem apresentando legendas com dois principais eixos: (i) do meio natural (topografia, hidrografia e hidrologia - fluvial e marítima, espécies vegetais, clima, etc.) e (ii) dos atributos dinâmicos, ou seja, aqueles que degradam o meio ambiente (descargas industriais, estradas, habitação e mineração, etc.). Associa-se aos agentes naturais e aos processos naturais as degradações provocadas pelo homem, como erosão do litoral, deslizamentos e outros (Journaux 1975), assim como, os aspectos relacionados à defesa e melhoramento desses ambientes.

Também, o índice de vulnerabilidade costeira, voltado à elevação do nível do mar, passou a ser determinado, a partir da Convenção das Nações Unidas - Painel Intergovernamental sobre Mudanças do Clima IPCC/92, tendo em vista a necessidade de "desenvolvimento de estudos sobre vulnerabilidade e de adaptação aos impactos às mudanças climáticas", como um compromisso assumido por todos os países que ratificaram a Convenção, entre eles o Brasil. Foi proposta aos seus integrantes a elaboração de planos integrados para a gestão costeira, recursos hídricos e agricultura, além de outros, levando em conta as relações desses recursos com as alterações do clima, visando o uso de tecnologias (Klein et al. 2001), medidas políticas, econômicas, sociais e ambientais, para que se possa atenuar os "efeitos negativos na economia, na saúde pública e na qualidade do meio ambiente" (BRASIL. MCT 1999, Carey \& Mieremet 1992), "concentrando o uso de metodologia comum entre os países", segundo Brewster (2002).

Em países com territórios costeiros, a avaliação da vulnerabilidade e do potencial de risco à comunidade (Gragnger \& Hayne 2001) é feita em planos e programas de gestão apresentados aos dirigentes, que assegurem o gerenciamento desses eventos, disponibilizando-lhes acesso rápido à informação ao estabelecerem medidas que orientem a população a enfrentá-los com maior segurança (White 1978). Para tanto, os estudos realizados na avaliação da vulnerabilidade costeira propõem quantificar os problemas relacionados aos processos costeiros naturais, como os de influência antrópica (Appebdini \& Fischer 1998).

A avaliação da vulnerabilidade está inserida, nos últimos anos, em estudos costeiros considerandose abordagens integradas e sistêmicas. A paisagem é analisada sob uma visão holística, onde as variáveis são definidas, segundo Brewster (2002), pelas características biofísicas e humanas, capazes de refletir as mudanças do comportamento em todo o sistema natural. Deste modo, para esse autor, as diversas variáveis podem ser agrupadas em categorias, que representam a natureza biológica, física, oceanográfica, natural ou humana, socioecônomica, e dos processos costeiros.

Ainda para Brewster (2002), a avaliação da vulnerabilidade ou da sensibilidade da linha de costa diz respeito tanto aos impactos antropogênicos como também aos impactos da hidrodinâmica e natureza do clima.

No Brasil, autores como Monteiro et al. (inédito), Crepani et al. (1996), Medeiros (1999), Sousa (1999) e Carvalho et al. (2003) estudaram a vulnerabilidade natural à erosão, para avaliar as condições restritivas do meio físico, em diversas áreas, no ordenamento territorial brasileiro. Tagliani (2002) usou a vulnerabilidade ambiental para representar a maior ou menor susceptibilidade a que um ambiente pode estar submetido a um impacto potencial, mediante o seu uso, na planície costeira do estado do Rio Grande do Sul.

A vulnerabilidade também vem sendo utilizada, além dos aspectos mencionados anteriormente, para o balizamento de futuras instalações de atividades econômicas de modo a considerar a capacidade de suporte dos ambientes terrestres e marinhos.

De tal modo, a necessidade de monitoramento da dinâmica costeira é uma questão que vem sendo defendida desde os anos 70 por White (1978), Appendini \& Fischer (1998). Porém, é nos anos 90, que se dá o crescimento relevante de instituições internacionais, no sentido de se determinarem índices de vulnerabilidade ambiental, visando "medir o estado do ambiente na busca de uma marca de nível pré-determinada" (Gowrie 2003), para ser aplicado à gestão da zona costeira. Por outro lado, tudo isso se alinha à evolução das geotecnologias destacando os sistemas de informações geográficas (SIG's), que permitem a inter-relação das escalas multitemporais entre os dados espaciais físicos, biológicos e socioeconômicos de forma integrada (Medeiros 1999), ao avaliar-se a vulnerabilidade ambiental, conforme mencionado por Nascimento \& Dominguez (2005).

Deste modo, este trabalho tem por objetivo o mapeamento da vulnerabilidade ambiental visando a gestão da zona costeira, tendo sido consideradas as diferentes características ambientais dos ecossistemas na delimitação de unidades com maior e menor resistência à implantação de futuras atividades produtivas, nos municípios de Belmonte e Canavieiras, situados no litoral Sul do estado da Bahia.

CONCEITUAÇÃO A noção de vulnerável, do latim Vulnerabilis, corresponde ao ponto mais fraco ou que passa a ser mais vulnerável, mais acessível aos ataques (Séguier 1935). A vulnerabilidade está sempre relacionada à maior ou menor fragilidade de um determinado ambiente. A vulnerabilidade costeira foi definida por Dal Cin \& Simeoni (1994) como um instrumento de planejamento e gerenciamento adequado do litoral. É também apontado por esses autores na definição de índices de vulnerabilidade e/ou risco costeiro - Coastal Vulnerability Index (CVI). Segundo o Coastal Services Center da National Oceanic and Atmospheric Administration (NOAA) (1999), o termo vulnerabilidade é definido como a "susceptibilidade de um meio ao impacto negativo com relação a um determinado risco". Para essa organização, os estudos da freqüência de desastre, risco e probabilidade têm sido componentes importantes para a análise da vulnerabilidade, e esta, constitui uma informação necessária 
para priorizar as ações de mitigação aos fenômenos naturais destrutivos.

Em 1999/2001, o U.S. Geological Survey (USGS) realizou estudo de vulnerabilidade para identificar áreas costeiras na América do Norte com maior susceptibilidade às cheias (Hammar-Klose et al., 2003). Com a provável subida do nível do mar serão acentuados assim, os riscos à inundação, erosão e deslizamento (Hoefel 1998, Muehe 2001, Klein et al. 2001), aumento da cunha salina nos aqüíferos subterrâneos, ameaça aos recursos do patrimônio histórico-cultural e a infraestrutura (Hammar-Klose et al. 2003, Nicholls 2004).

LOCALIZAÇÃO E CARACTERIZAÇÃO DA ÁREA ESTUDADA A área estudada compreende terras da planície costeira, dos tabuleiros e de serras dos municípios de Belmonte e Canavieiras no estado da Bahia, Brasil, localizadas entre as coordenadas geográficas de $15^{\circ} 20^{\prime}$ e $16^{\circ} 05^{\prime}$ de latitude sul e $38^{\circ} 50^{\prime}$ e $39^{\circ} 30^{\prime}$ ' de longitude oeste de Gr. W., nas Regiões denominadas Costa do Cacau e Costa do Descobrimento, respectivamente, por conta dos municípios litorâneos que as compõem. Para efeito de análise, foram também consideradas nesta pesquisa as terras situadas na parte norte da Ilha de Comandatuba, incluindo-se aí o Hotel Transamérica, pertencente ao município de Una. A foz do rio Doce é o ponto que define o limite entre os municípios de Una e Canavieiras, reconhecendo-se, portanto, duas Administrações Municipais neste território da Ilha de Comandatuba.

O Estado da Bahia contava, em 2002, com uma população estimada em 13 milhões de habitantes (SEI, 2002), e a sua zona costeira, com cerca de 4 milhões de habitantes, residentes a menos de $50 \mathrm{~km}$ da linha de costa, o que equivale a uma densidade de $140 \mathrm{hab} / \mathrm{km}$, representando seis vezes mais a média estadual, que é de $23 \mathrm{hab} / \mathrm{km}$. Esta densidade é fruto da história do povoamento da zona costeira brasileira que se inicia desde os primeiros decênios do século XVI na zona litorânea, com a exploração da madeira, conhecido este como o ciclo do pau-brasil (Caesalpinia echinata) (Pinto 1965).

Do final do século XIX até a década de 80 do século seguinte, a cultura do cacau se expandiu mais intensamente pelo litoral Sul da Bahia e norte do Espírito Santo, e em Canavieiras e Belmonte a cultura dominou as planícies aluviais, em Neossolos Flúvicos, quando passou a ter um maior incremento após a sua valorização no mercado mundial (CEPLAC 1975).

No final do século XX, a cultura do cacau entra em decadência, fazendas são abandonadas e trabalhadores migram para os centros urbanos. A partir desse contexto, Canavieiras teve o maior crescimento da população urbana em detrimento da rural, registrando, em 2000, 26.161 habitantes na zona urbana e apenas 8.974 (IBGE, 2000) na zona rural, três vezes menos. No mesmo período, outras atividades agrícolas, como o mamão, a mandioca e a silvicultura, ocuparam os Tabuleiros, em Latossolos distróficos, principalmente no Município de Belmonte. A silvicultura, base florestal da agroindústria da celulose (Eucaliptus granfis), implantada a partir dos anos 80 , é hoje a principal ativida- de agrícola da região do Extremo Sul, vindo a ocupar as terras de capoeira e de pastagens, instaladas após a exaustão dos recursos madeireiros.

No século XXI outras atividades passam a ocupar esse território. Em Canavieiras, a partir de 2003/2004, na planície costeira, nos terraços marinhos holocênicos e áreas úmidas, cerca de 17 empreendimentos de carcinicultura são instalados com capital financiado pelo Banco do Nordeste, quando não de origem privada. São empresários vindos predominantemente do Sul do país, que investem no cultivo de camarão voltado à exportação, ao mercado Europeu e Sul do Brasil. Além disso, mais recentemente, a partir de 2005, são os estrangeiros, principalmente italianos e portugueses, que têm investido em equipamentos turísticos, com a expansão desta atividade na planície costeira, em Belmonte e Canavieiras. Têm ocupado áreas de restinga e pontais arenosos, adjacentes aos manguezais.

Deste modo, a planície costeira, os tabuleiros e as serras dos municípios de Belmonte e Canavieiras, vêm sendo ocupados por atividades econômicas, constituídos por terrenos de diversidade quanto à origem do material e a topografia. A intensificação do uso nas últimas décadas nestes ambientes instáveis motivou o desenvolvimento deste estudo, visando a avaliação da vulnerabilidade ambiental.

\section{CRITÉRIOS PARA ESTABELECER AS CLASSES DE VULNERABILIDADE NOS MUNICÍPIOS DE BELMONTE E CANAVIEIRAS - BAHIA}

Integração e análise de dados Tendo por base os mapeamentos de uso da terra/vegetação (tipo de uso), geologia (litologia), solos (tipo) e declividade (classe) procedeu-se o desenvolvimento de rotinas para a conversão de dados vetoriais em formato matricial (raster), com tamanho de célula de 100m. Foi utilizado o aplicativo Arc View $\square 3.2$, para o desenvolvimento das operações de geoprocessamento, com a extensão Spatial Analyst. O Índice de Vulnerabilidade foi calculado pela soma - operações algébricas -, dos valores atribuídos a cada classe de um determinado tema (raster), considerando o grau de sensibilidade de cada atributo selecionado, pelos seus respectivos pesos, utilizando a ferramenta map calculator. Nove classes de vulnerabilidade foram individualizadas posteriormente agrupadas em 5 classes: baixa, baixa à média, média, alta e muito alta conforme comentado mais adiante.

Vulnerabilidade ambiental - critérios adotados $\mathrm{Na}$ determinação das classes de vulnerabilidade foram atribuídos valores empíricos de "1" a " 5 ", considerando o grau de sensibilidade de cada unidade para o atributo selecionado. Foi adotada como referência a metodologia do U. S. Geological Survey - USGS (Thieler \& Hammar-Klose 1999) aplicada para um trecho do litoral atlântico Norte Americano, em função de uma possível elevação do nível do mar. Os critérios qualitativos adotados neste trabalho foram adaptados de Tagliani (2002), e estão apresentados no quadro 1.

As classes de vulnerabilidade resultantes desta análise representam condições ambientais que apontam 
Quadro 1 - Variáveis e critérios adotados.

\begin{tabular}{l|l}
\hline Variáveis & Critérios \\
\hline Geologia & Tempo geológico e fragilidade \\
\hline Solos & Maturidade pedogenética \\
\hline Declividade & Variação de declividade \\
\hline $\begin{array}{l}\text { Vegetação/ } \\
\text { Uso da terra }\end{array}$ & Proteção da paisagem e biodiversidade da biota \\
\hline
\end{tabular}

para diferentes fragilidades ou potencialidades naturais. As classes de mais baixa vulnerabilidade ambiental apresentam menores riscos aos efeitos da ocupação, tendo sido identificadas duas situações distintas: áreas intensamente ocupadas e áreas com estágios mais conservados pela cobertura da vegetação natural. As classes de alta e muita alta vulnerabilidade ambiental apresentam altos riscos a danos ambientais, algumas já comprometidas devido aos efeitos antropogênicos decorrentes principalmente de desmatamentos e ocupações desordenadas.

GEOLOGIA Na classificação de vulnerabilidade deste tema foi considera a idade geológica. Assim quanto mais antiga a idade da rocha menor valor atribuído à vulnerabilidade que variou de "1" a "5", conforme apresentado na tabela 1. Considerando o acentuado grau de instabilidade da linha de costa, reflexo dos vários processos cos-

Tabela 1 - Valores de Vulnerabilidade Ambiental para as unidades litológicas, presentes nos municípios de Belmonte e Canavieiras - Bahia.

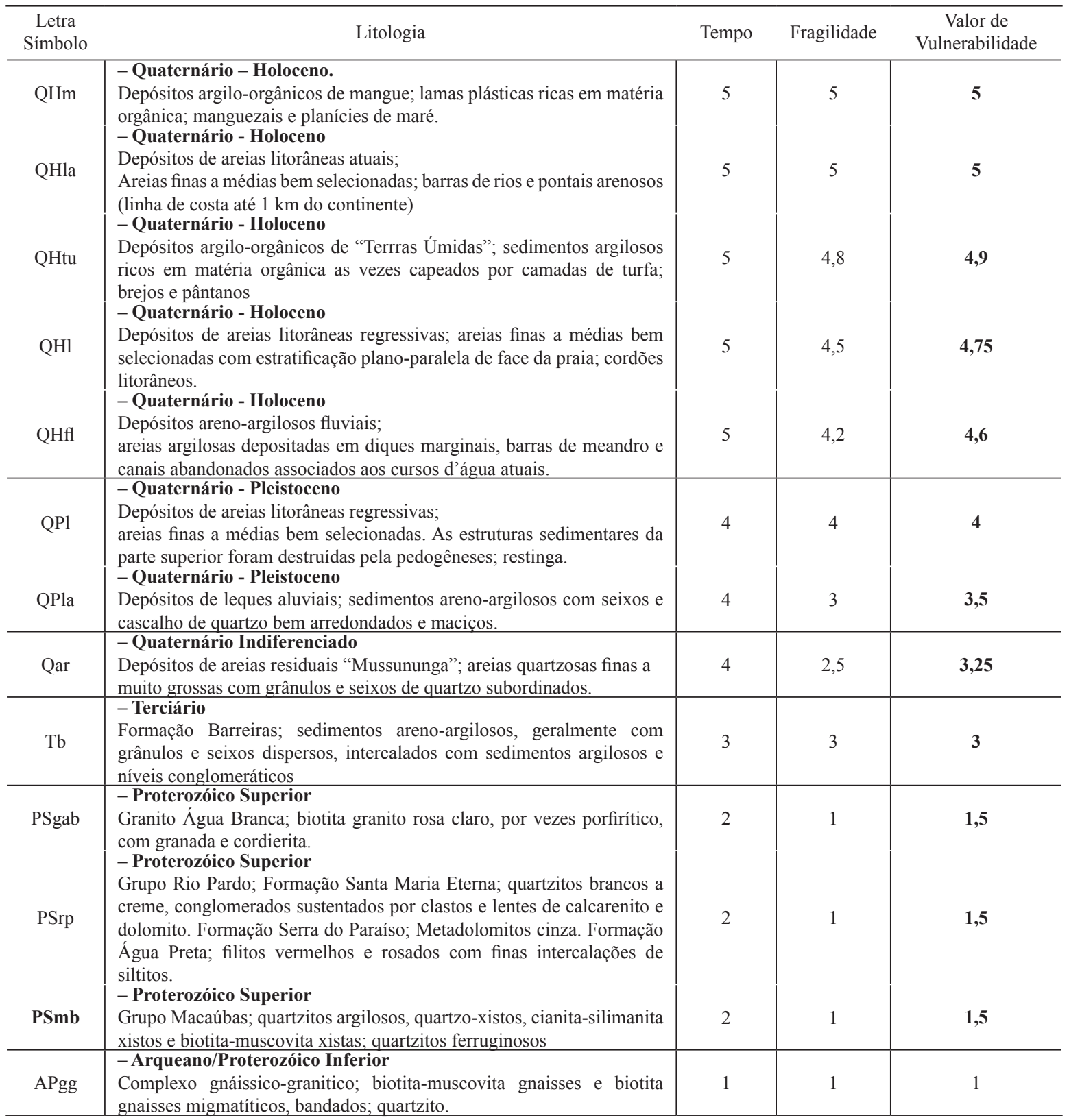

Fonte: adaptado de Crepani et al. (1996), Nascimento \& Dominguez (2005) 
teiros atuantes - marítmos, continentais e atmosféricos (Dominguez et al. inédito, Muehe 2001) foi atribuído o valor " 5 " a uma faixa com $1 \mathrm{~km}$ de largura considerada à partir da linha de costa. O mesmo valor foi atribuído aos depósitos argilo-orgânicos de mangue.

Foi ainda considerado em nossa análise o grau de fragilidade litológica representado pelo grau de coesão dos minerais em cada unidade mapeada. Desta maneira, aos sedimentos inconsolidados foram atribuídos valores entre "5" e "4,2", de maior significação quanto à vulnerabilidade intrínseca, representados pelos depósitos flúvio-marinhos, flúvio lagunares, marinhos e fluviais, datados do Quaternário (Holoceno). Para os depósitos datados do Pleistoceno, foram atribuidos valores entre "4" e "3,0". Os depósitos quaternários indiferenciados de areias residuais "mussunungas" receberam o valor de "2,25". Os sedimentos da Formação Barreiras, representam uma situação intermediária, valor "3”, no que diz respeito ao grau de coesão dos sedimentos. As litologias mais antigas, como os metassedimentos dos Grupos Água Branca, Macaúbas e Rio Pardo, datadas do Proterozóico Superior e as litologias do Arqueano/Proterozóico Inferior receberam valor "1". A figura 1 apresenta a espacialização final dos valores de vulnerabilidade.

\section{Classes de Vulnerabilidade}

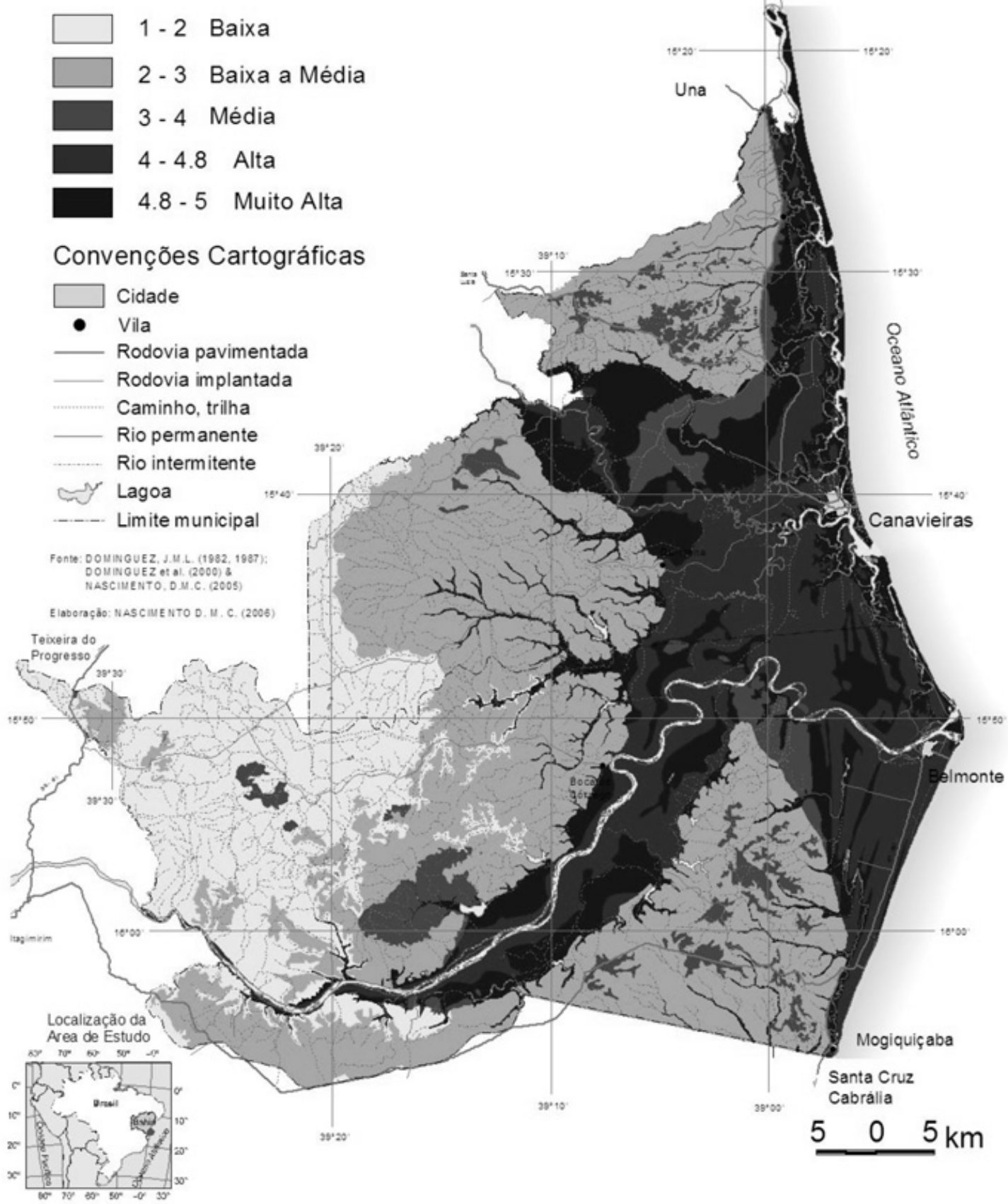

Figuara 1 - Espacialização das classes de vulnerabilidade atribuídas às diferentes unidades geológicas, dos municípios de Belmonte e Canavieiras - Bahia. 
SOLOS Para os Solos, valores de vulnerabilidade variando de " 1 " a " 5 " foram atribuídos às diferentes classes de solo, considerando-se o grau de maturidade do solo, conforme apresentado no tabela 2. Observa-se que aos solos mais desenvolvidos foram atribuídos os menores valores. Assim os Latossolos receberam valor "1" e os Argissolos valor "2". Para todos os solos menos evoluídos constituídos por sedimentos inconsolidados adotou-se os maiores valores " 5 " e " 4 ". O valor intermediário de "3" foi atribuído aos Espodossolos. A figura 2 apresenta a espacialização, destes valores de vulnerabilidade atribuídos aos solos.

O agrupamento das classes de solos em associações deve-se ao nível de generalização da escala de mapeamento e ao predomínio da primeira classe sobre a segunda. Os valores para as diferentes associações de solos foram determinados a partir de um esquema de ponderação adaptado de Crepani et al. 1996, Medeiros 1999 e Sousa 1999. Na unidade de solo formada por uma única classe adotou-se $100 \%$ do valor. Nas associações formadas por duas classes de solos foram atribuídos $60 \%$ do valor de " 1 " a " 5 " para a primeira classe de solo, conforme a sua abrangência, e $40 \%$ para a segunda classe, de menor abrangência. Nas associações constituídas por três classes de solos, foram adotados $60 \%, 30 \%$ e $10 \%$, correspondendo respectivamente à primeira, segunda e terceira classe de solo. Os Latossolos (LVAd1) e os Argissolos (PVAd3) por apresentarem uma área de abrangência maior que as classes anteriores, foram consideradas $90 \%$ do valor atribuído à primeira classe de solo da associação, e $10 \%$ a segunda classe de solo - os Neossolos Flúvicos, conforme apresentado na tabela 3 .

USO DA TERRA Para estabelecer as classes de vulnerabilidade para os diferentes tipos de uso da terra levouse em consideração o papel da vegetação como manto protetor da paisagem. A cobertura vegetal responde pela estabilidade dos processos morfodinâmicos, preconiza Tricart (1977). Para o autor a cobertura vegetal densa apresenta capacidade de frear o "desencadeamento de processos mecânicos da morfogênese". A baixa energia para a remoção de material e transporte, favorece os processos pedogenéticos enquanto restringe os processos morfogenéticos. Por outro lado, a falta de cobertura florestal densa contribui para a instabilidade ambiental, com o desenvolvimento da morfogênese. Para Christofoletti (1974) as características da cobertura vegetal vão influenciar na variedade das modalidades e intensidades dos processos, contribuindo para a acumulação ou subtração de matéria. De acordo com Ross (1991) a remoção da cobertura vegetal, parcial ou total, tornando o terreno exposto, facilita o escoamento pluvial concentrado e diminuindo a infiltração de água no solo.

Desta maneira de acordo com os critérios estabelecidos por Tricart (1977), Monteiro et al. (inédito), Crepani et al. (1996), Tagliani (2002), e Nascimento \& Dominguez (2005), foram adotados os valores mais baixos, entre " 1 " e "3" para os terrenos protegidos que apresentam maior densidade da cobertura vegetal, enquanto
Tabela 2 - Valores de vulnerabilidade ambiental atribuídos às diferentes classes de solos, presentes nos municipios de Belmonte e Canavieiras - Bahia.

\begin{tabular}{|c|c|c|}
\hline $\begin{array}{l}\text { Letra símbolo } \\
\text { das classes }\end{array}$ & Classes de Solos & $\begin{array}{l}\text { Valor de } \\
\text { Vulnerabilidade }\end{array}$ \\
\hline GT/SM & $\begin{array}{l}\text { Glei Tiomórfico/Solos } \\
\text { Indiscriminados de Mangue }\end{array}$ & 5 \\
\hline OX & Organossolo Háplico & 5 \\
\hline GXbd & Gleissolo Háplico & 5 \\
\hline RUbe & Neossolo Flúvico Tb eutrófico & 4 \\
\hline RQg & $\begin{array}{l}\text { Neossolo Quartzarênico } \\
\text { Hidromórfico }\end{array}$ & 4 \\
\hline $\mathrm{EKg}$ & Espodossolo Hidromórfico & 3 \\
\hline PVAd & $\begin{array}{l}\text { Argissolo Vermelho-Amarelo } \\
\text { distrófico }\end{array}$ & 2 \\
\hline LAd & Latossolo Amarelo distrófico & 1 \\
\hline LVAd & $\begin{array}{l}\text { Latossolo Vermelho-Amarelo } \\
\text { distrófico }\end{array}$ & 1 \\
\hline
\end{tabular}

Fonte: Adaptado de Crepani et al. (1996), Nascimento \& Dominguez (2005).

os terrenos com coberturas herbáceas ou gramíneas, com culturas de ciclos curtos ou expostos receberam valores elevados entre "4" e "5", considerando a baixa densidade de cobertura, conforme o tabela 4 . O alto grau de fragilidade ambiental do ecossistema dos manguezais mesmo sendo portador de uma densa cobertura natural, justificou a atribuição do valor máximo de " 5 ", o mesmo valor atribuído aos reservatórios de carcinicultura.

$\mathrm{O}$ ecossistema de manguezal apresenta características intrínsecas de seu substrato que o tornam rico, produtivo e ao mesmo tempo frágil às alterações ambientais, com repercussões quase sempre negativas. A atividade da carcinicultura por criar um ambiente também bastante sensível, uma vez que os camarões podem ser vetores de uma infinidade de vírus transmissores de doenças (Schmidt, 2005), com alto potencial de risco de contaminação dos manguezais, recebeu também o valor "5". Este valor foi ainda atribuído aos corpos d'águas como as lagoas e rios e canais, às terras de brejo, aos bancos arenosos, e às áreas urbanas ou construídas como às estações de tratamento de esgoto. Na classe das terras agrícolas atribuiu-se excepcionalmente o valor " 5 " à cultura do mamão, por receber sistematicamente produtos químicos durante todo o período produtivo para combate às pragas. $\mathrm{O}$ mesmo aconteceu com a cana-de-açúcar localizada nas aluviões. O tabela 5 apresenta os valores de vulnerabilidade atribuídos a cada tipo de uso da terra e a figura 3 apresenta a espacialização, destes valores de vulnerabilidade.

DECLIVIDADE A declividade é o principal índice morfométrico utilizado na avaliação da vulnerabilidade.

Simielli (1981) modifica a classificação de declividades de Chiarini \& Donzeli (1973) quando subdividiu a primeira classe de até $12 \%$, em duas classes, a menor de $5 \%$ e de 5 a $12 \%$. A classe de $12 \%$ está associada à utilização das práticas agrícolas, uma vez que até esta classe $12 \%$, inexistem restrições à mecani- 


\section{Classes de Vulnerabilidade}

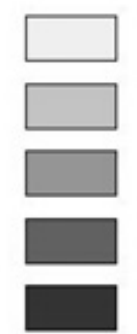

\section{1 - 2 Baixa}

2 - 3 Baixa a Média

3 - 4 Média

4 - 4.8 Alta

4.8 - 5 Muito Alta

\section{Convenções Cartográficas}

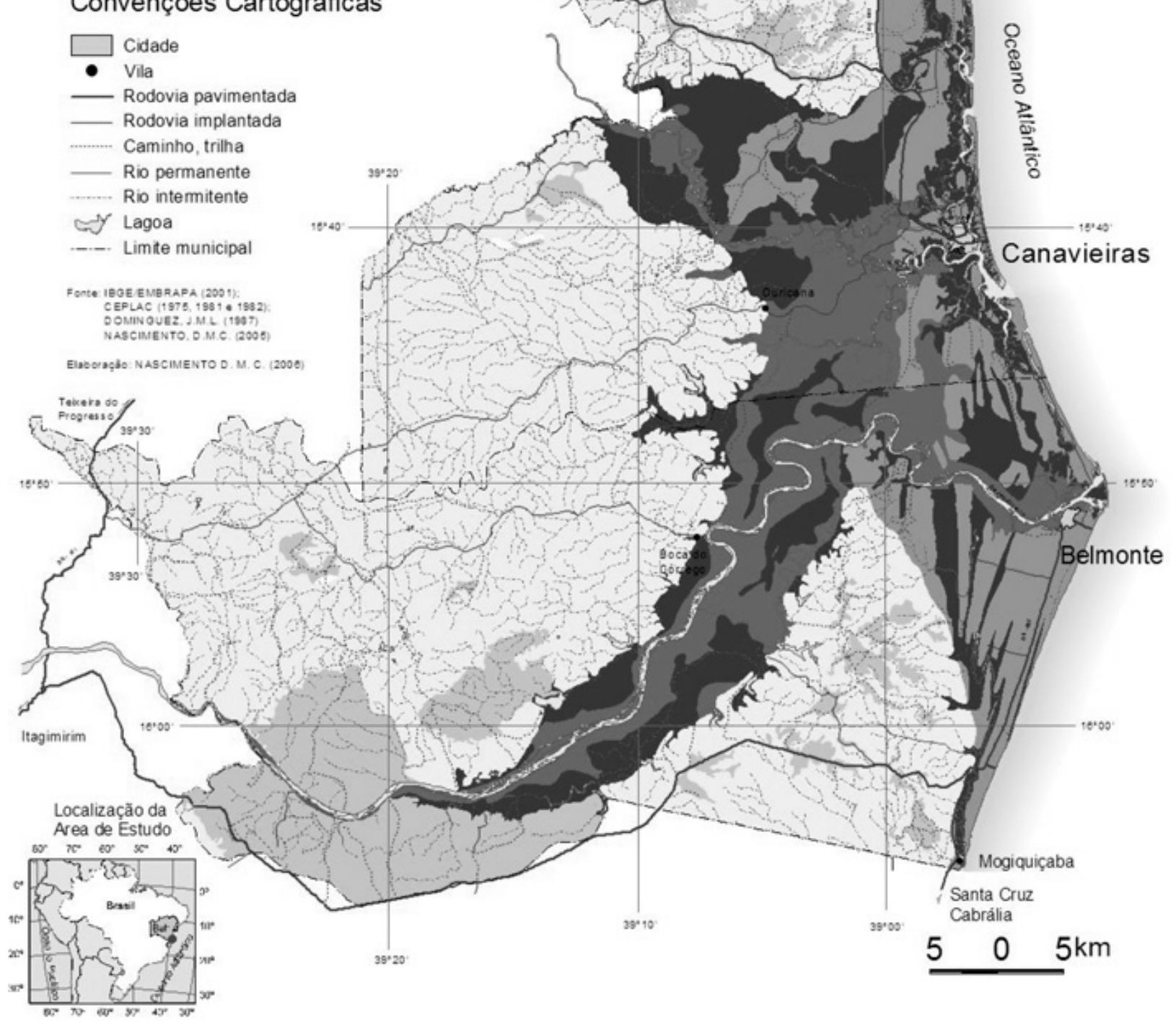

Figura 2 - Espacialização das classes de vulnerabilidade atribuidas ás diferentes associações de solos, dos municípios de Belmonte e Canavieiras - Bahia.

zação. Já na classe acima de $20 \%$, apresenta problemas no aproveitamento agrícola com grandes restrições de utilização da terra para este tipo de uso.

Tagliani (2002) adotou a declividade de 45\% como limite determinado pelo código florestal para a preservação florestal, e de $10 \%$, como o limite da declividade na área da planície costeira do Rio Grande do Sul.

Considerando que a área de estudo apresenta dois níveis topográficos bem distintos, a planície costeira e o tabuleiro costeiro, separados por uma falésia inativa com cerca de 40 metros de desnível, adotou-se neste trabalho as classes de declividade modificada de Tagliani (2002). Desta maneira as classes foram: até $10 \%$ para a planície costeira, por se apresentar muito plana a plana, e de $10 \%, 20 \%, 30 \%, 45 \%$ e desta até $52 \%$ para os tabuleiros costeiros e serras. A classe de 
Tabela 3 - Valores de vulnerabilidade ambiental atribuidos para as associações de solos, presentes nos municípios de Belmonte e Canavieiras - Bahia.

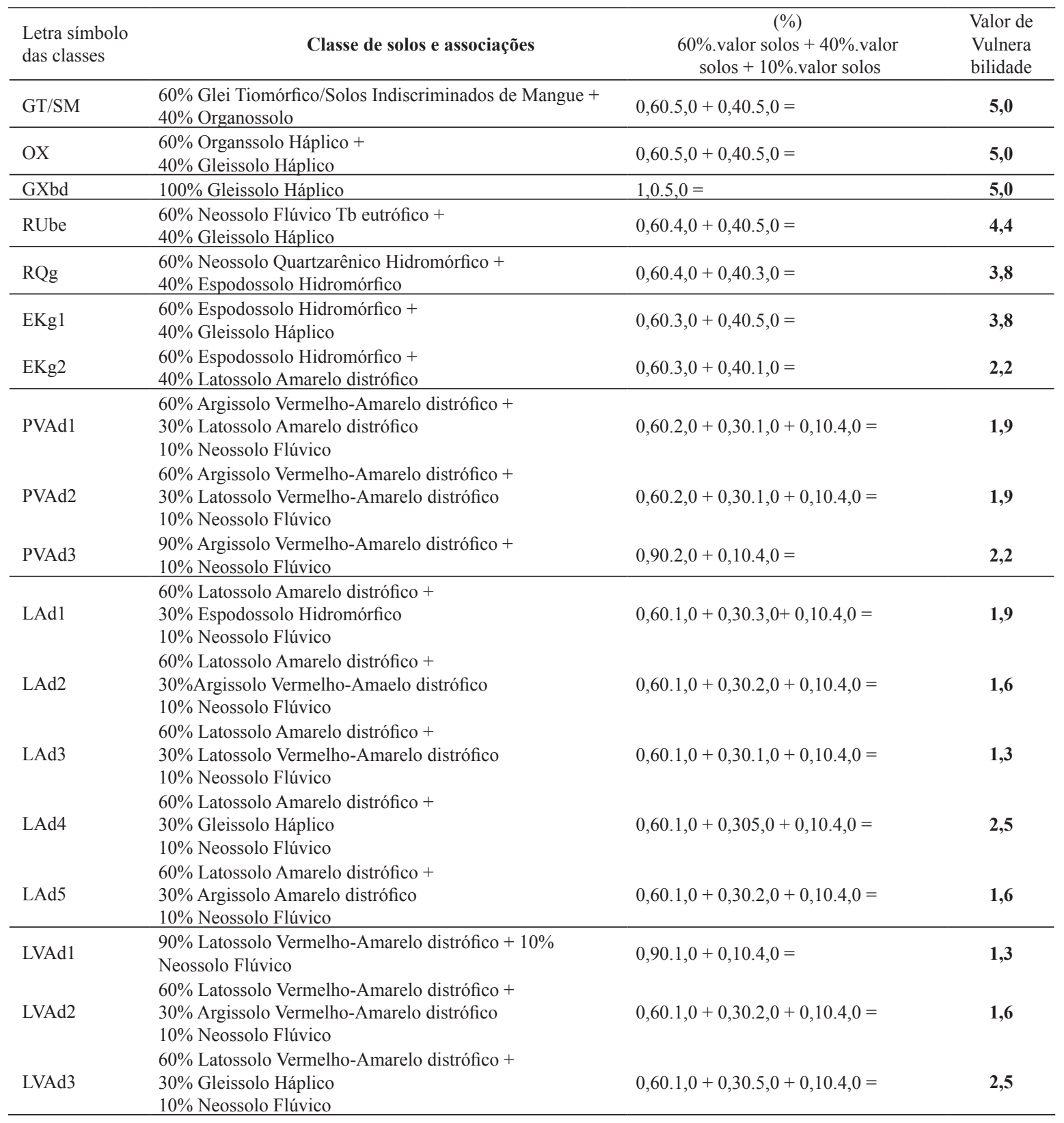

Fonte: Modificado de Crepani et al. (1996), Medeiros (1999), Sousa (1999).

10 a $20 \%$ normalmente delimita as duas unidades (Fig. 4). Os valores de vulnerabilidade atribuídos a cada uma destas classes estão apresentados no tabela 6 .

\section{RESULTADO DA VULNERABILIDADE AMBIEN-}

TAL A partir dos mapas de vulnerabilidade ambiental de cada tema foi produzido o mapa de vulnerabilidade ambiental final para os municípios de Belmonte e Canavieiras, em 5 classes ( 1 a 5 ), designadas em: baixa, baixa a média, média, alta e muito alta (Fig. 5). Posteriormente estas classes foram mensuradas as percentagens conforme mostra a tabela 7. Os resultados obtidos são discutidos a seguir.

\section{Classe de muito alta vulnerabilidade ambiental (va-}

Tabela 4 - Valores de vulnerabilidade ambiental para as diferentes categorias de uso, nos municipios de Belmonte e Canavieiras - Bahia.

\begin{tabular}{lll}
\hline $\begin{array}{l}\text { Letra Símbolo } \\
\text { das classes }\end{array}$ & Categorias & $\begin{array}{l}\text { Valor de } \\
\text { Vulnerabilidade }\end{array}$ \\
\hline TU/C & Terra Urbana ou & $\mathbf{4 / 5}$ \\
TA & Tenstruída & $\mathbf{1 , 5 / 5}$ \\
P & Pastagem Agrícola & $\mathbf{4}$ \\
TF & Terra Florestal & $\mathbf{1 / 3}$ \\
TU & Terra Úmida & $\mathbf{4 / 5}$ \\
TA & Terra Árida & $\mathbf{5}$ \\
TCA & Terra com Água & $\mathbf{5}$ \\
\hline
\end{tabular}

Fonte: Adaptado de Crepani et al. (1996), Nascimento \& Dominguez (2005). 
Tabela 5 - Valores de vulnerabilidade ambiental para as unidades de uso da terra, nos municípios de Belmonte e Canavieiras - Bahia.

\begin{tabular}{|c|c|c|}
\hline Letra símbolo & Categoria de Uso da Terra e associações de uso da terra & Valor \\
\hline & Terra Urbana ou Construída & \\
\hline TUCc & Núcleo urbano consolidado - cidade & 5,0 \\
\hline TUCv & Vila & 4,0 \\
\hline TUCh & Área com empreendimento hoteleiro, bar e restaurante associada à cultura de coco. & 5,0 \\
\hline TUCrl & Área com equipamento residencial (sítio e chácara) ou loteada para veraneio associada à cultura de coco. & 4,0 \\
\hline TUCic & Área da industria de celulose & 4,0 \\
\hline \multirow[t]{3}{*}{ TUCo } & Área com uso de argila e/ou caulim para o fabrico do tijolo, telha e/ou cerâmica - olaria & 5,0 \\
\hline & Depósito de lixo desativado & 5,0 \\
\hline & Depósito de lixo em uso & 5,0 \\
\hline \multirow[t]{2}{*}{ ETE } & Estação de Tratamento de Esgoto & 5,0 \\
\hline & Terra Agrícola & \\
\hline TAca & Cultura de cacau em área de Floresta Ombrófila Densa Aluvial ou em Floresta Ombrófila Densa de Terras Baixas. & 2,0 \\
\hline TAco & Cultura de coco-da-baía em área de restinga & 2,0 \\
\hline TAcn & Cana de açúcar em aluvião & 5,0 \\
\hline TAcf & Cultura de café & 2,0 \\
\hline TAcm & Cultura de mamão & 5,0 \\
\hline TAs & Silvicultura - maciço florestal homogêneo de eucalipto & 1,5 \\
\hline \multirow[t]{2}{*}{ TAcd } & $\begin{array}{l}\text { Cultura diversificada; frutífera (mamão, coco da baía, banana, abacaxi, maracujá principalmente) e pequena gleba } \\
\text { com mandioca, milho, feijão ou pastagem }\end{array}$ & 3,0 \\
\hline & Pastagem & \\
\hline P1 & Pastagem semi-intensiva destinada principalmente à pecuária leiteira. & 4,5 \\
\hline Pc & $\begin{array}{l}\text { Pastagem semi-intensiva destinada principalmente à pecuária de corte, associada a pequenas parcelas de cultivo de } \\
\text { mandioca }\end{array}$ & 4,0 \\
\hline \multirow[t]{2}{*}{ Psvg } & Terra sem cobertura vegetal ou desmatada com finalidade agro-pastoril. & 5,0 \\
\hline & Terra Florestal & \\
\hline TFo & Floresta Ombrófila Densa em estágio inicial e médio de antropismo. & 1,0 \\
\hline TFoc & Floresta Ombrófila Densa em estágio avançado de antropismo ou vegetação secundária - capoeira. & 1,5 \\
\hline TFmr & Mata de Restinga & 1,5 \\
\hline TFra & Restinga arbustiva & 2,0 \\
\hline TFrh & $\begin{array}{l}\text { Restinga herbácea com trecho associado à pastagem nativa e/ou cultivo de coco-da-baía e a pequenas glebas de } \\
\text { cultivo de subsistência }\end{array}$ & 3,0 \\
\hline \multirow[t]{2}{*}{$\mathrm{TFcm}$} & Vegetação herbácea - Campo de "mussununga" & 3,0 \\
\hline & Terra Úmida & \\
\hline TUmg & Manguezais, uso comercial e pesca artesanal de crustáceo e molusco associada a planície de maré. & 5,0 \\
\hline TUvaa & Terra com vegetação arbustiva e/ou arbórea, de pântano ou brejo & 4,0 \\
\hline TUvh & Terra com vegetação herbácea de brejo, pastada por rebanho bovino em determinado período do ano & 5,0 \\
\hline \multirow[t]{2}{*}{ TUba } & Banco arenoso & 5,0 \\
\hline & Terra Árida & \\
\hline \multirow[t]{2}{*}{ TAsp } & Sedimento de praia atual & 5,0 \\
\hline & Terra Com Água & \\
\hline TCAcr & $\begin{array}{l}\text { Reservatório destinado principalmente à carcinicultura - camarão } \\
\text { Rio permanente }\end{array}$ & $\begin{array}{l}5,0 \\
5,0\end{array}$ \\
\hline $\mathrm{La}$ & Lagoa permanente & 5,0 \\
\hline ni & Uso não identificado & 3,0 \\
\hline
\end{tabular}

Fonte: Modificado de Crepani et al. (1996), Nascimento \& Dominguez (2005).

Tabela 6 - Valores de vulnerabilidade ambiental para as unidades de declividades, nos municípios de Belmonte e Canavieiras - Bahia.

\begin{tabular}{lll}
\hline $\begin{array}{l}\text { Descrição das classes } \\
\text { de relevo }\end{array}$ & $\begin{array}{l}\text { Declividade } \\
\text { \% }\end{array}$ & $\begin{array}{l}\text { Valor de } \\
\text { Vulnerabilidade }\end{array}$ \\
\hline Muito Plano a Plano & $0-10$ & 1 \\
Suave Ondulado & $10-20$ & 2 \\
Ondulado & $20-30$ & 3 \\
Muito Ondulado & $30-45$ & 4 \\
Forte Ondulado & $45-52$ & 5 \\
\hline
\end{tabular}

Fonte: Adaptado de Tagliani (2002); Nascimento \& Dominguez (2005).
Tabela 7 - Áreas e percentuais das classes de vulnerabilidade ambiental, nos municípios de Belmonte e Canavieiras - Bahia.

\begin{tabular}{|c|c|c|c|}
\hline $\begin{array}{l}\text { Intervalo de classes } \\
\text { de vulnerabilidade }\end{array}$ & $\begin{array}{c}\text { Valor de } \\
\text { vulnerabilidade }\end{array}$ & $\begin{array}{c}\text { Área } \\
\text { ha }\end{array}$ & $\begin{array}{c}\text { Área } \\
\%\end{array}$ \\
\hline $5-8$ & 1 & 76.300 & 22,5 \\
\hline $8-10$ & 2 & 72.700 & 21,5 \\
\hline $10-12$ & 3 & 89.850 & 26,6 \\
\hline $12-15$ & 4 & 63.700 & 18.8 \\
\hline $15-19$ & 5 & 36.000 & 10,6 \\
\hline \multicolumn{2}{|l|}{ Total } & 338.550 & 100 \\
\hline
\end{tabular}




\section{Classes de Vulnerabilidade}

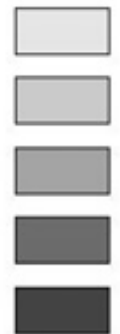

1 - 2 Baixa

2 - 3 Baixa a Média

3 - 4 Média

$4-4.8$ Alta

4.8 - 5 Muito Alta

\section{Convenções Cartográficas}
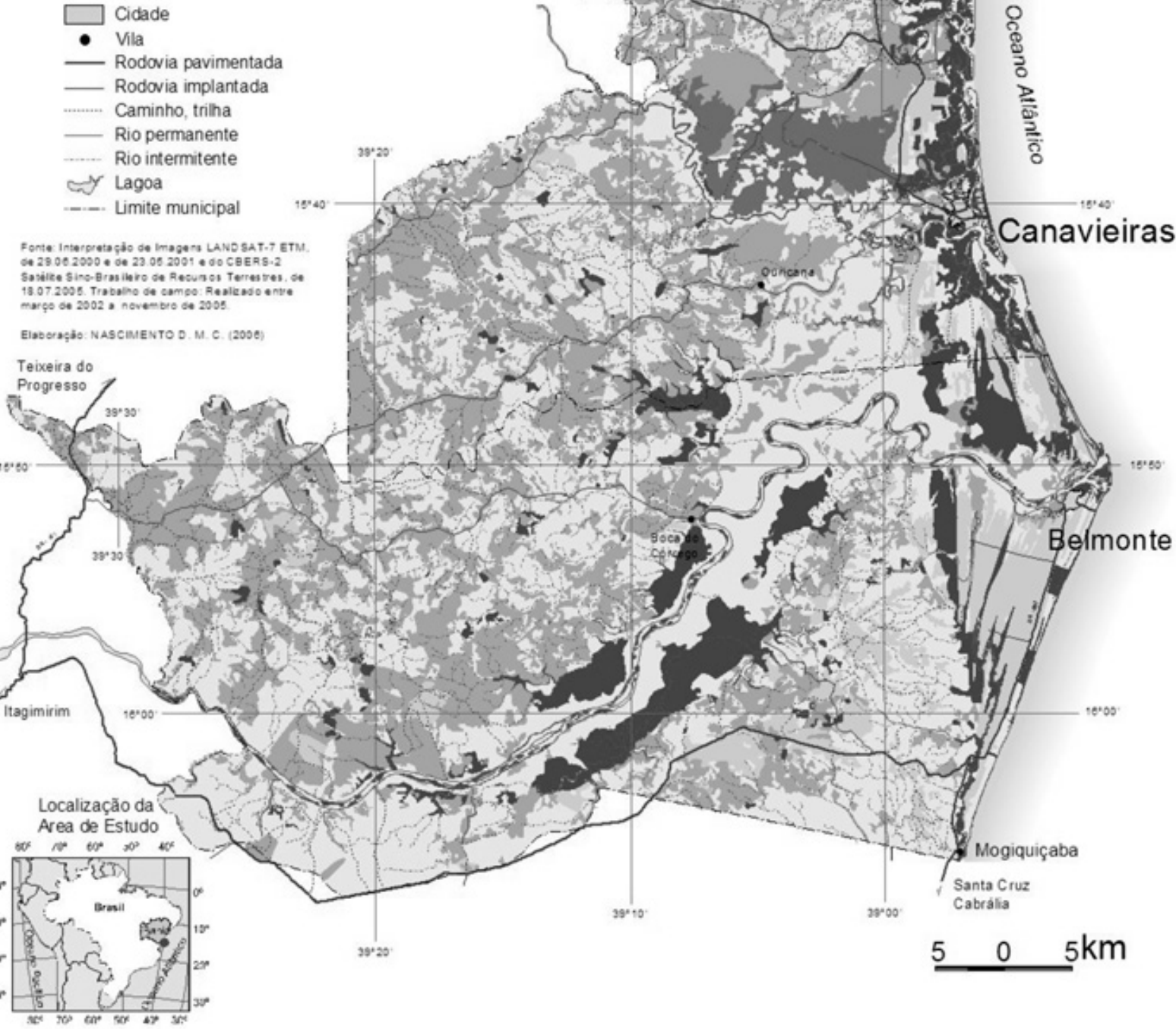

Figura 3 - Espacialização das classes de vulnerabilidade atribuídos aos diferentes usos da terra, dos municípios de Belmonte e Canavieiras - Bahia.

lor 5) Esta classe que engloba 36.000 hectares (10,6 $\%$ ), inclui todas as áreas de manguezal, as terras úmidas e os depósitos ou terraços flúvio-lagunares, que ocupam áreas rebaixadas (Dominguez et al. inédito). Esta classe engloba, portanto, os ecossistemas mais sensíveis da região. Estão sujeitos às inundações, seja, pelas águas pluviais, seja pelo transbordamento dos rios Jequitinhonha ou Pardo, ou mesmo pelas marés, que funcionam como fatores restritivos ao uso agrícola. Nas superfí- cies topograficamente muito baixas, de 0 a 3 metros de altitude, predominam os Organossolos e os Gleissolos, onde os riscos de contaminação também são elevados.

Classe de alta vulnerabilidade ambiental (valor 4) Esta classe ocupa uma área total de 63.700 hectares $(18,8 \%)$, inclui os terraços marinhos, formados por depósitos de areias litorâneas regressivas quaternárias (pleistocênico e holocênico). São áreas bastante planas 


\section{Classes de Declividade (\%)}

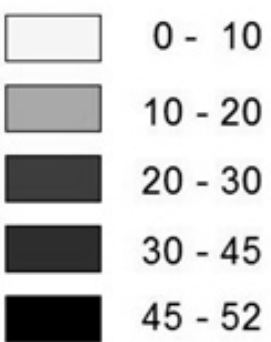

\section{Convenções Cartográficas}

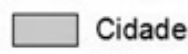

\footnotetext{
- Vila

- Rodovia pavimentada

Rodovia Implantada

Caminho, trilha

Rio permanente

Rio in termitente

Wr Lagoa

-..- Limite municipal
}

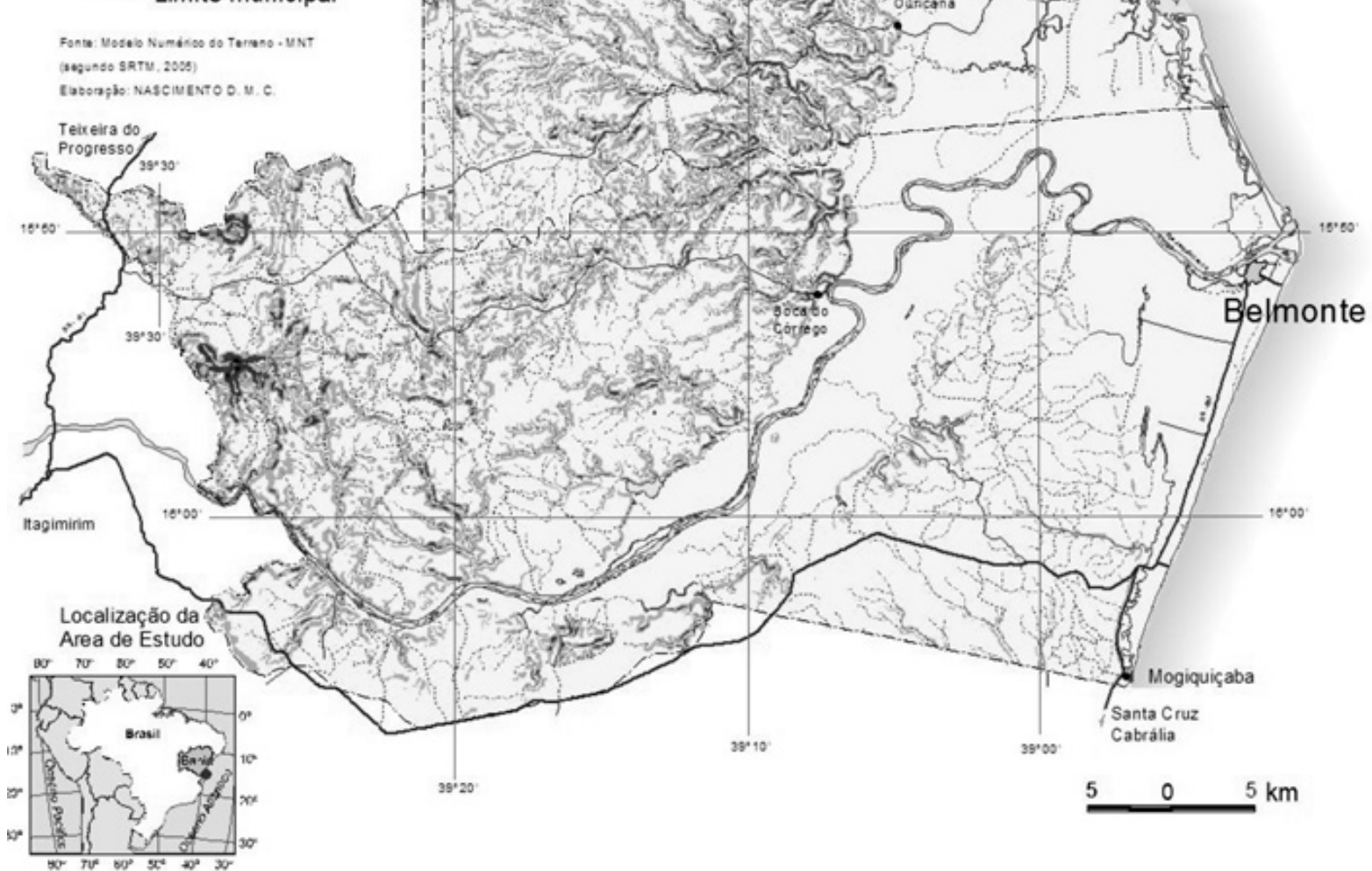

Figura 4 - Espacialização das classes de vulnerabilidade com base na declividade do terreno nos municipios de Belmonte e Canavieiras - Bahia.

com altimetria variando entre 0 a 8 metros, com pequena declividade ( 0 a $10 \%)$. Estes terraços apresentam micro relevo, em forma de cordões litorâneos, morfologia constituída de cristas alternadas com áreas deprimidas úmidas, com o lençol freático aflorante. Apresentam restrições aos usos, pois, a descaracterização deste ambiente, através de terraplenagem para implantação de atividades turística, agropastoril ou mesmo residencial, certamente, acarretará na destruição das cristas praiais e o aterramento das depressões, ainda preservadas em Belmonte e totalmente descaracterizadas em Canavieiras, assumindo, portanto, caráter irrevessível na paisagem da planície costeira. Em quase toda sua extensão predominam os Neossolos Quartzarênicos. Alguns trechos apresentam pastagens plantadas e eventualmente naturais onde se encontram as manchas urbanas. Incluem-se trechos da linha de costa, apresentando localmente erosão costeira acentuada, como na Ilha de 
Classes de Vunerabilidade Ambiental

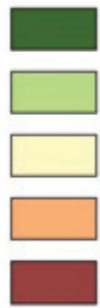

\section{5 - 8 Baixa}

8 - 10 Baixa a Média

10 - 12 Média

12 - 15 Alta

$15-19$ Muito Alta

\section{Convenções Cartográficas}

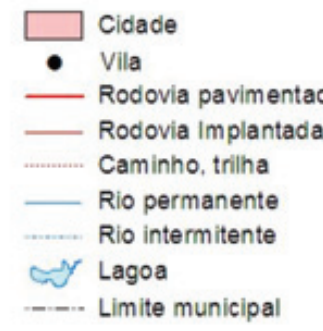

--- Limite municipal

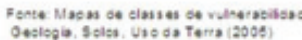

ovelvisese.

Eageroẹto NASCMENTO D.M.C.

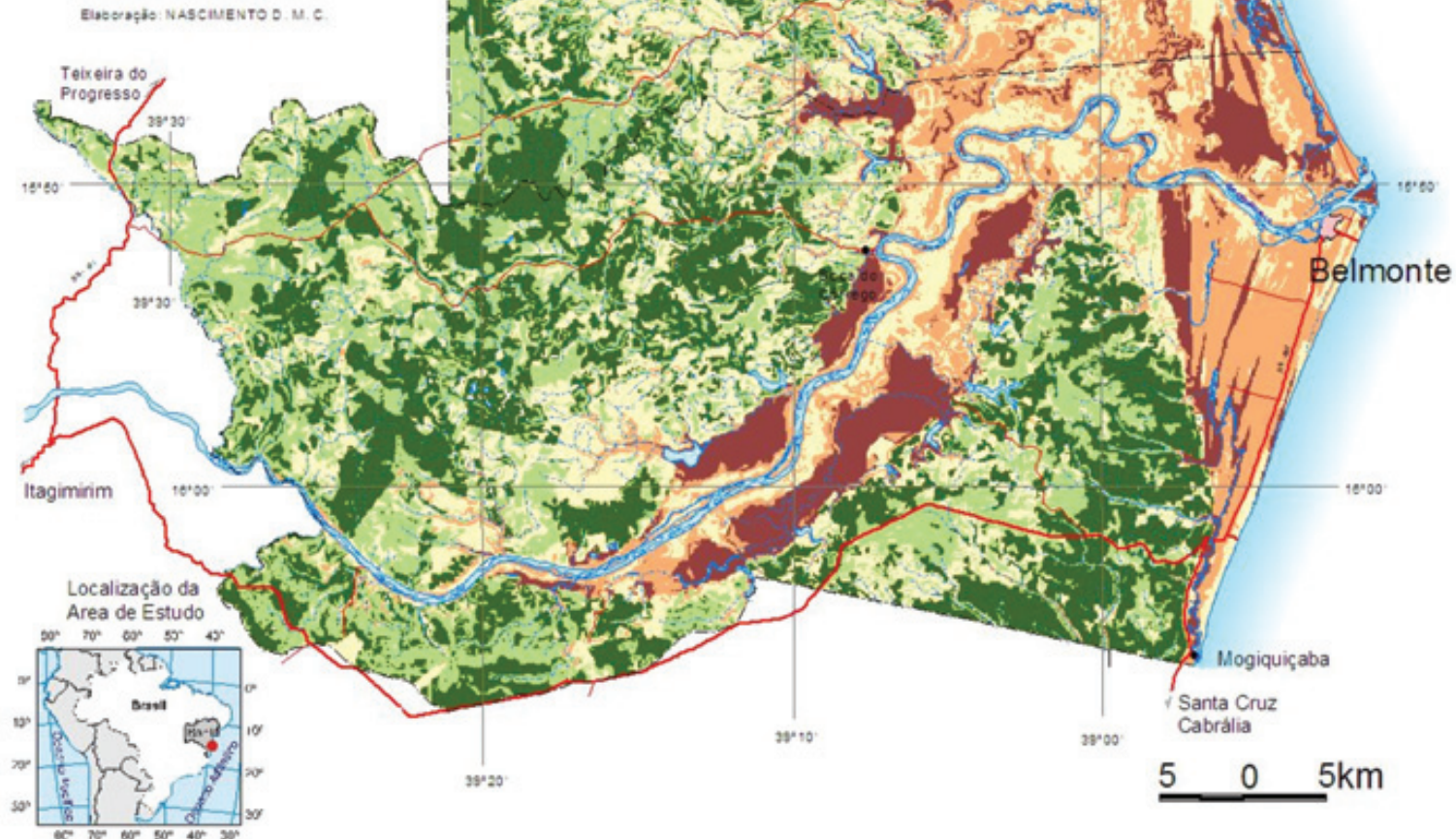

Figura 5 - Espacialização das classes de vulnerabilidade ambiental, nos municípios de Belmonte e Canavieiras - Bahia.

Atalaia, onde foi construída a estrada de acesso aos hotéis e sítios neste local.

Nesta classe, ainda estão incluídas partes dos terraços fluviais e os bancos arenosos presentes no leito do rio Jequitinhonha cobertos por pastagens.

Classe de média vulnerabilidade ambiental (valor 3) Esta classe ocorre predominantemente na planície costeira e secundariamente nos tabuleiros costeiros, totalizando 89.850 hectares $(26,6 \%)$. Na planície costeira inclui em quase toda sua extensão os Neossolos Flúvicos eutróficos, constituídos por sedimentos areno- argilosos, que formam os substratos dos diques marginais dos principais rios. Estes solos são recobertos por vegetação Floresta Ombrófila aluvial - mata cabruca - que associada à lavoura cacaueira se alterna com a atividade de pastagem, principalmente, a pecuária bovina de corte. São, portanto, áreas sujeitas à inundação no período das cheias dos rios Jequitinhonha e Pardo.

Nos tabuleiros, a classe de média vulnerabilidade compreende as declividades entre $10 \%$ e $20 \%$, incluindo os solos expostos, as pastagens, as culturas de mamão e coco-da-baía, assim como, pequenas glebas de cultivos de subsistência, com destaque para a man- 
dioca associada geralmente a pequenas propriedades rurais e aos Assentamentos de Reforma Agrária - implantados pelo INCRA.

Classe de baixa à média vulnerabilidade ambiental (valor 2) Esta classe inclui predominantemente as áreas de tabuleiro e das serras, totalizando 72.700 hectares $(21,5 \%)$, constituídos principalmente por Latossolos e Argissolos. Nesta classe a cobertura original da Floresta Ombrófila Densa foi removida, sendo hoje ocupada por pastagens e áreas de cultivos, principalmente de eucalipto. Inclui ainda nesta classe as areias residuais conhecidas como campos de "mussunungas", encontradas em superfícies planas dos tabuleiros costeiros, com cobertura vegetal de caráter herbácea, em Espodossolos.

Classe de baixa vulnerabilidade ambiental (valor 1) Estas áreas ocorrem associadas aos tabuleiros costeiros e serras em altitudes que variam de 40 a 400 metros, e onde predominam os Latossolos Amarelos e os Argissolos distróficos. A monocultura de eucalipto (Eucaliptus granfis), destinada à fábrica da Veracel Celulose S/A. para a produção de celulose, e principalmente, os remanescentes da Floresta Ombrófila densa nos diversos estágios de antropismo são dominantes nesta classe, definindo assim, conjuntamente com a alta estabilidade das litologias e solos a baixa vulnerabilidade destas áreas. Ocupam uma área total de 76.300 hectares $(22,5 \%)$.

Deste modo, a integração dos elementos físicos e antrópicos permitiram uma ampla classificação das áreas dos municípios de Belmonte e Canavieiras, segundo seu maior ou menor grau de vulnerabilidade. A identificação das cinco classes de vulnerabilidade apresentadas neste estudo, permite estabelecer critérios de suporte para os novos empreendimentos, principalmente, naquelas áreas que apresentaram vulnerabilidade ambiental muito alta. Para estas áreas se devem estabelecer limitações de uso e ocupação, devendo ser também consideradas às questões como a da remoção da cobertura natural. Por outro lado, as áreas menos vulneráveis apresentam maior potencialidades de uso, face a maior sustentabilidade oferecida pelos fatores físicos da geologia, rochas mais coesas e solos mais estáveis, como no caso dos tabuleiros.

CONSIDERAÇÕES FINAIS A espacialização das classes de vulnerabilidade ambiental mostrou que as classes de mais baixa vulnerabilidade são aquelas que apesar de serem ocupadas por atividades agropastoris, apresentam os solos mais estáveis, evoluídos e litologias antigas, ou seja, as áreas cobertas pelos tabuleros costeiros e serras. A baixa declividade da planície costeira contribuiu para diminuir os valores da vulnerabilidade ambiental nesta área. Ainda assim, $100 \%$ das classes de alta e muito alta vulnerabilidade encontramse na planície costeira o que corresponde a $29,4 \%$ da área total dos muncipíos de Belmonte e Canavieiras.

As análises mostraram que os sistemas naturais na zona costeira dos municípios de Belmonte e Canavieiras apresentam dois diferentes graus de vulnerabilidade ambiental. Na planície costeira predomina a alta e muito alta vulnerabilidade ambiental e nos tabuleiros a baixa e média vulnerabilidade ambiental, apesar das diferentes intensidades de uso da terra nestas áreas, prevalecendo de uma forma geral os condicionantes intrínsicos destes ecossistemas. Deste modo, as áreas de alta e muito alta vulnerabilidade ambiental, ainda que com baixa ocupação, devem ser amparadas por legislação ambiental e os instrumentos de gestão.

Um estudo como este, se torna importante na medida em que possa ser utilizado como um norteador das políticas de gestão para esta parte da zona costeira e contribuir para que as novas ocupações e o desenvolvimento econômico e social sejam compatibilizados com a preservação ambiental.

Agradecimentos À Fundação de Amparo à Pesquisa do Estado da Bahia (FAPESB) pelo apoio financeiro a esta pesquisa realizada para a tese de Doutorado em Geologia da UFBA (Processo No 40031280).

\section{Referências}

Appendini C.M. \& Fischer D.W. 1998. Hazard management planning for severe storm erosion. Shore \& Beach, 66:58.

Brailovsky A.E. 1978. El medio ambiente y la integración Latinoamericana. Integración Latinoamericana, 3:2034.

BRASIL. Ministério da Ciência e Tecnologia. 1999. Convenção sobre mudanças do clima: programa mudanças climáticas. Disponível em: < http://www.met. gov.br/Clima/brasl/obj_ac01.htm.>. Acesso em: 24 jun. 2004.

Brewster L.F.S. 2002. The development of a comprehensive littoral vulnerability assessment approach for a Small Island Developing State: a case study for Barbados. In: International Conference 'Littoral 2002': Porto, 6,
Proceedings, p. 189-197.

Carey J.J. \& Mieremet R.B. 1992. Reducing vulnerability to sea level rise: international initiatives. Ocean Coastal Management, 18:161-177.

Carvalho G.M.B.S., Souza M.J.N.de., Santos, S.M. 2003. Análise da vulnerabilidade à erosão: bacias dos rios Aracatiaçu e Aracatimirim (CE). In: Simpósio Brasileiro de Sensoriamento Remoto, Belo Horizonte, 11, Anais eletrônicos, 1 CD-ROM.

COMISSÃO EXECUTIVA DO PLANO DA LAVOURA CACAUEIRA (CEPLAC) 1975. História econômica e social. In: (eds.) Diagnóstico socioeconômico da Região Cacaueira. Ilhéus (BA), CEPLAC, v. 8.

Christofoletti A. 1974. Geomorfologia. Edgard Blücher, São Paulo, 149 p. 
Crepani E., Medeiros J.S., Azevedo L.G., Hernandez Filho P., Florenzano T.G., Duarte V. 1996. Curso de sensoriamento remoto aplicado ao zoneamento ecológico-econômico: metodologia desenvolvida para subsidiar o Zoneamento Ecológico-Econômico. INPE, São José dos Campos, 25 p.

Dal Cin R. \& Simeoni U. 1994. A model for determining the classification, vulnerability and risk in the Southern Coastal Zone of the Marche (Italy). Journal of Coastal Research, 10:18-29.

Gowrie M. N. 2003. Environmental vulnerability index for the Island of Tobago, West Indies. Disponível em: $<$ http;//www.consecol.org/vol7/iss2/art11>. Acesso em: 13 set. 2004.

Granger K. \& Hayne M. 2001. Natural hazards and the risks they pose to South-East Queensland. Australian Geological Survey Organisation, Australian. Disponível em: <http://www.gagov.au/urban/projects/cities. jsp>. Acesso em: 29 jul. 2004.

Hammar-Klose E.S., Pendleton E.A., Thieler E.R., Williams S.J. 2003. Coastal vulnerability Assessment of Cape Cod National seashore to sea-level rise. USGS, Menlo Park, CA. Disponível em: <http://www.pubs.usgs.gov/ of/2002/of02-233/caco.htm>. Acesso em: 10 jul. 2004.

Hoefel F.G. 1998. Morfodinâmica de praias arenosas oceânicas: uma revisão bibliográfica. Itajaí, Editora da Univali, $92 \mathrm{p}$.

INSTITUTO BRASILEIRO DE GEOGRAFIA E ESTATÍSTICA (IBGE) 2001. Censo demográfico 2000. Disponível em: <http://www.ibge.gov.br> Acesso em: 20 jun. 2002.

Journaux A. 1975. Légende pour une carte de l'environnement et de sa dynamique. Centre de Géomorphologie du C.N.R.S., Caen.

Klein R.J.T., Nicholls R.J., Ragoonaden S., Capobianco M., Aston J., Buckley E.N. 2001. Technological options for adaptation to climate change in coastal zones. Journal of Coastal Research, 17:532-543.

Medeiros J.S.de. 1999. Bancos de dados geográficos e redes neutrais artificiais: tecnologias de apoio à gestão do território. Tese de Doutoramento, Faculdade de Filosofia, Letras e Ciencias Humanas, Universidade de São Paulo, 220 p.

Muehe D. 2001. Critérios morfodinâmicos para o estabelecimento de limites da orla costeira para fins de gerenciamento. Revista Brasileira de Geomorfologia, 2:35-44.

Nascimento D.M.C. \& Dominguez J.M.L. 2005. O mapa de vulnerabilidade ambiental como subsídio à gestão da zona costeira: o exemplo da planície costeira de Belmonte-BA. In: Congresso Brasileiro de Cartografia, 22, Anais, p.1-6.
Nicholls R.J. 2004. Report to the European Union on the Survas: Project (ENV4-CT98-0775). Middlesex University. Disponível em: <www.survas.mdx.ac.uk>. Acesso em: 06 jul.2004.

NATIONAL OCEANIC AND ATMOSPHERIC ADMINISTRATION (NOAA) 1999. Vulnerability assessment: 1999. Disponível em: <http://www.csc. noaa.gov/products/nchaz/htm/tut.htm>. Acesso em: 26 jul. 2004

Pinto D.M.M. 1965. Povoamento. In: IBGE (ed.) Geografia do Brasil. Rio de Janeiro, 485 p.

Ross J.L.S. 1991. Geomorfologia ambiente e planejamento. 2. ed. São Paulo, Contexto, 84 p.

Schmdt A. 2005. Camarões podem propagar doenças. Jornal A Tarde, Salvador, 24 maio 2005, caderno Ambiente \& Vida, p. 2.

Séguier J.de. 1935. Diccionário prático illustrado. Porto, Chardron, $1779 \mathrm{p}$.

SUPERINTENDÊNCIA DE ESTUDOS ECONÔMICOS E SOCIAIS DA BAHIA 2002 (SEI). Anuário estatístico da Bahia. Salvador, v. 16, 643 p.

Simielli M.E.R. 1981. Variação espacial da capacidade de uso da terra: um ensaio metodológico de cartografia temática, aplicado ao Município de Jundiai-SP. Dissertação de Mestrado, Faculdade de Filosofia, Letras e Ciências Humanas, Universidade de São Paulo, 88 p.

Sousa C.J.da.S.de. 1999. Carta de vulnerabilidade à erosão como subsídio ao zoneamento ecológico-econômico em áreas intensamente antropizada. Dissertação de Mestrado, INPE, $155 \mathrm{p}$.

Tagliani C.R.A. 2002. Técnica para avaliação da vulnerabilidade de ambientes costeiros utilizando um Sistema Geográfico de Informações. Porto Alegre, UFRGS. Disponível em: <http://www.fatorgis.com.br>. Acesso em: 10 nov. 2003.

Thieler E.R. \& Hammar-Klose E. 1999. National assessment of coastal vulnerability to sea level rise: preliminary results for the US. Atlantic Coast. USGS, Washington. Disponível em: <http://pubs.er. usgs.gov/index.ofr99593/htm>. Acesso em: 09 ago. 2004.

Tricart J. 1977. Ecodinâmica. Rio de Janeiro, Recursos Naturais e Meio Ambiente, 1, IBGE, 97 p.

White G. 1978. Natural hazards management in the Coastal Zone. Shore and Beach, 46:15-17.WORLD RESOURCES INSTITUTE. 2001. Relatório alerta para a crescente destruição das áreas costeiras do mundo. Tradução de M. C. Zinato. Disponível em: <www.ces. fau.edu/online>. Acesso em: 19 abr. 2001.

Manuscrito ID 11962

Submetido em 01 de agosto de 2008 Aceito em 12 de agosto de 2009 